Supplement of

\title{
North Atlantic Ocean-Atmosphere Driven Variations in Aerosol Evolution along Lagrangian Cold-air Outbreak Trajectories
}

Kevin J. Sanchez et al.

Correspondence to: Kevin J. Sanchez (kevin.j.sanchez@nasa.gov) and Richard H. Moore (richard.h.moore@nasa.gov) 

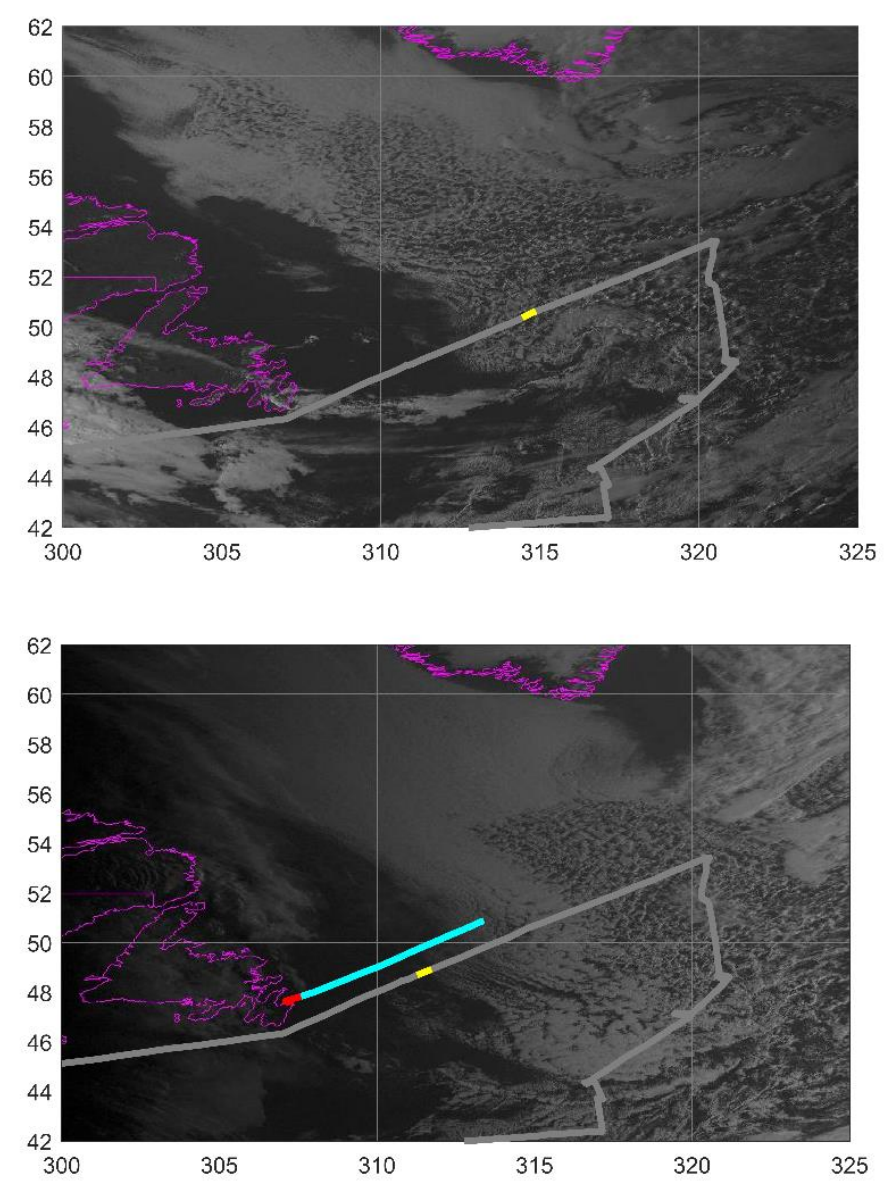

Figure S1. (top) 18 September 1945z (bottom) 19 September 1015z. Cyan and red lines represent the flight track at altitudes $>3 \mathrm{~km}$ and $<3 \mathrm{~km}$, respectively, \pm 1 hour from the satellite image time. The yellow line represents the ship position \pm 1 hour from the satellite image time. The gray line is the entire ship track for the NAAMES3 campaign. 

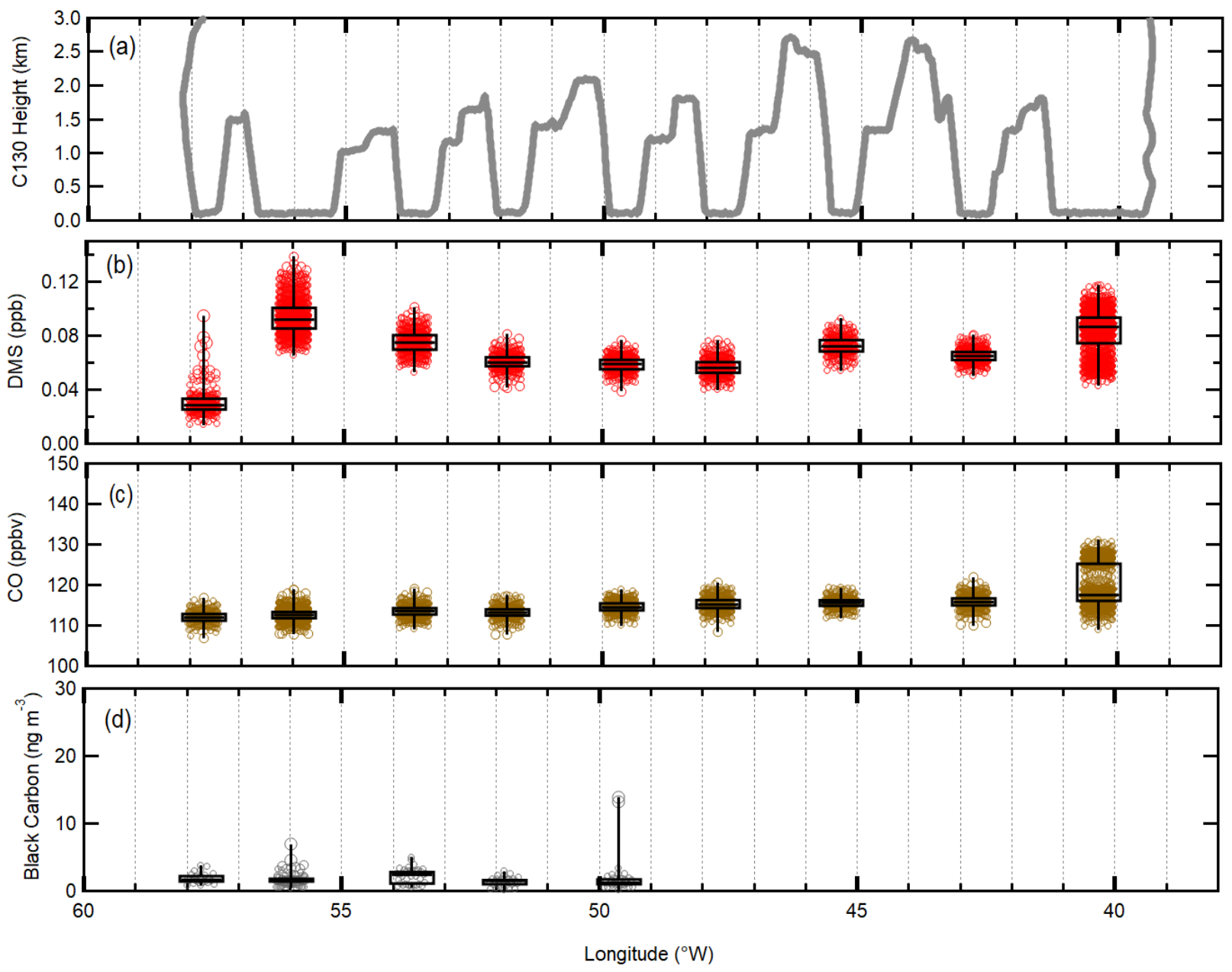

Figure S2. The (a) C130 altitude, (b) surface DMS, (c) carbon monoxide and (d) black carbon for 17 September. All measurements are presented as a function of longitude, consistent with Figure 3 measurements. 

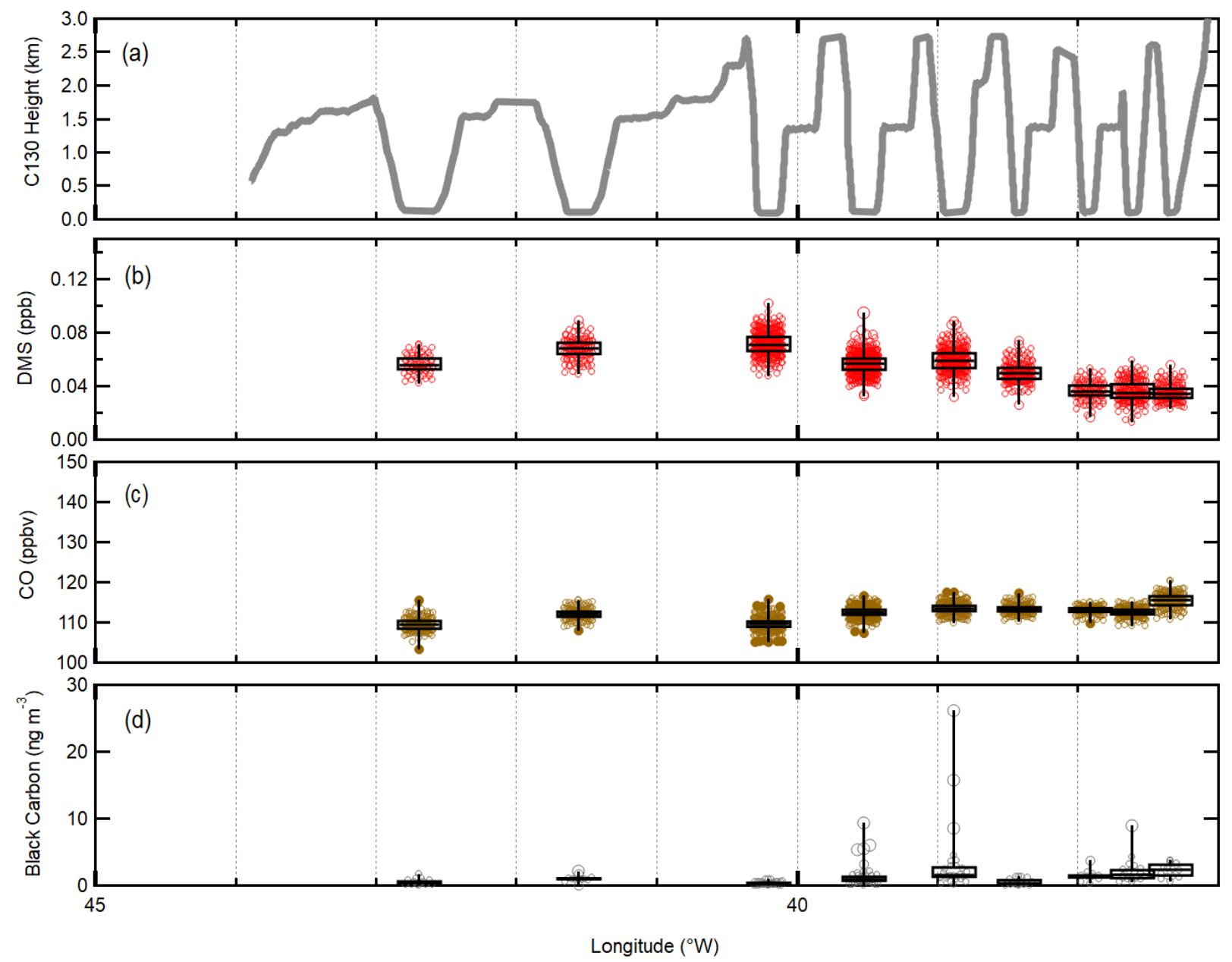

Figure S3. The (a) C130 altitude, (b) surface DMS, (c) carbon monoxide and (c) black carbon for 19 September. All measurements are presented as a function of longitude, consistent with Figure 4 measurements. 


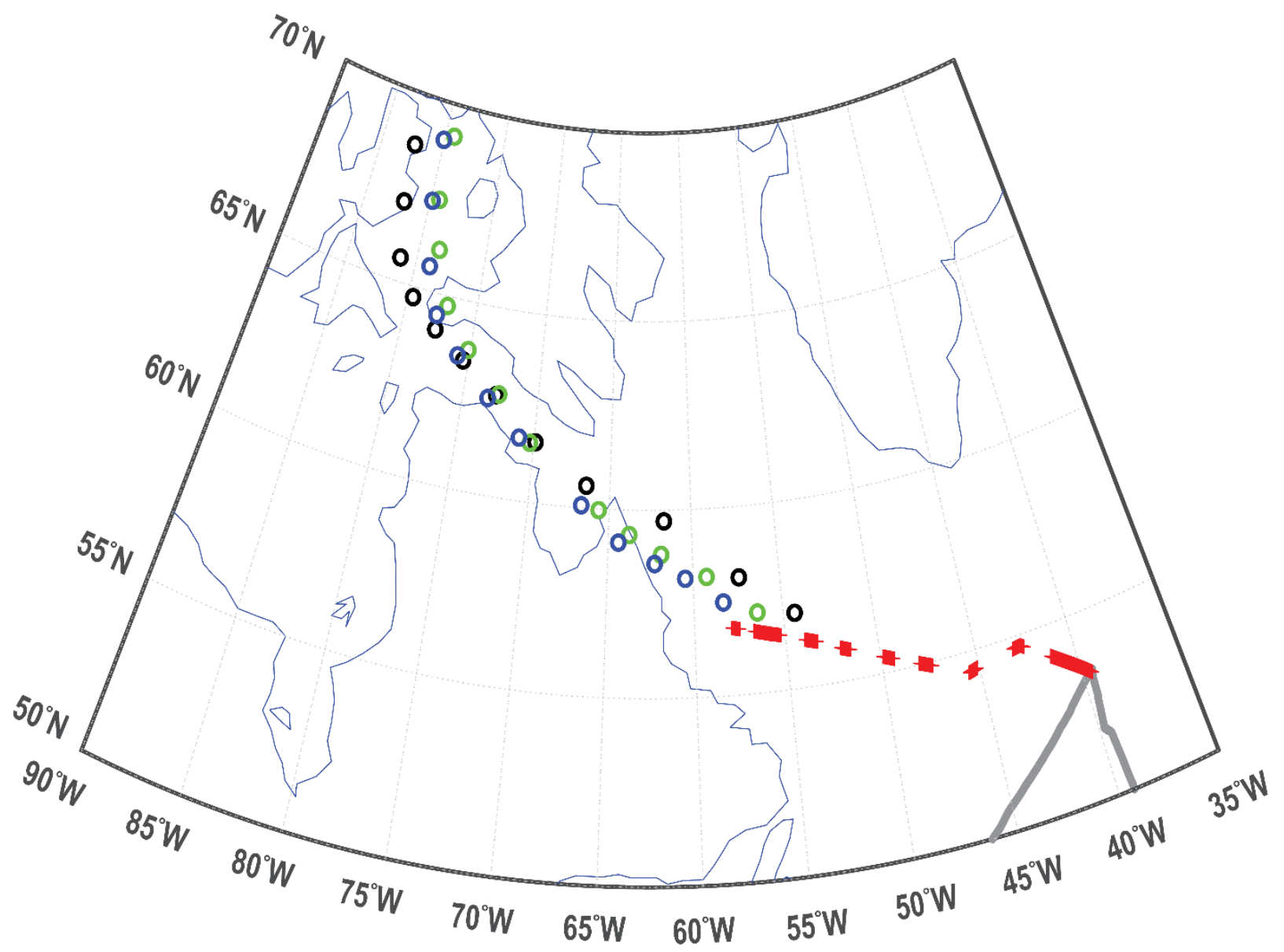

Figure S4. 3-Day FLEXPART back trajectories initialized at the three western most C130 near-surface legs (red) in a closed-cell region (black), cloud-free region (blue) and the transition zone (green) on September 17. 


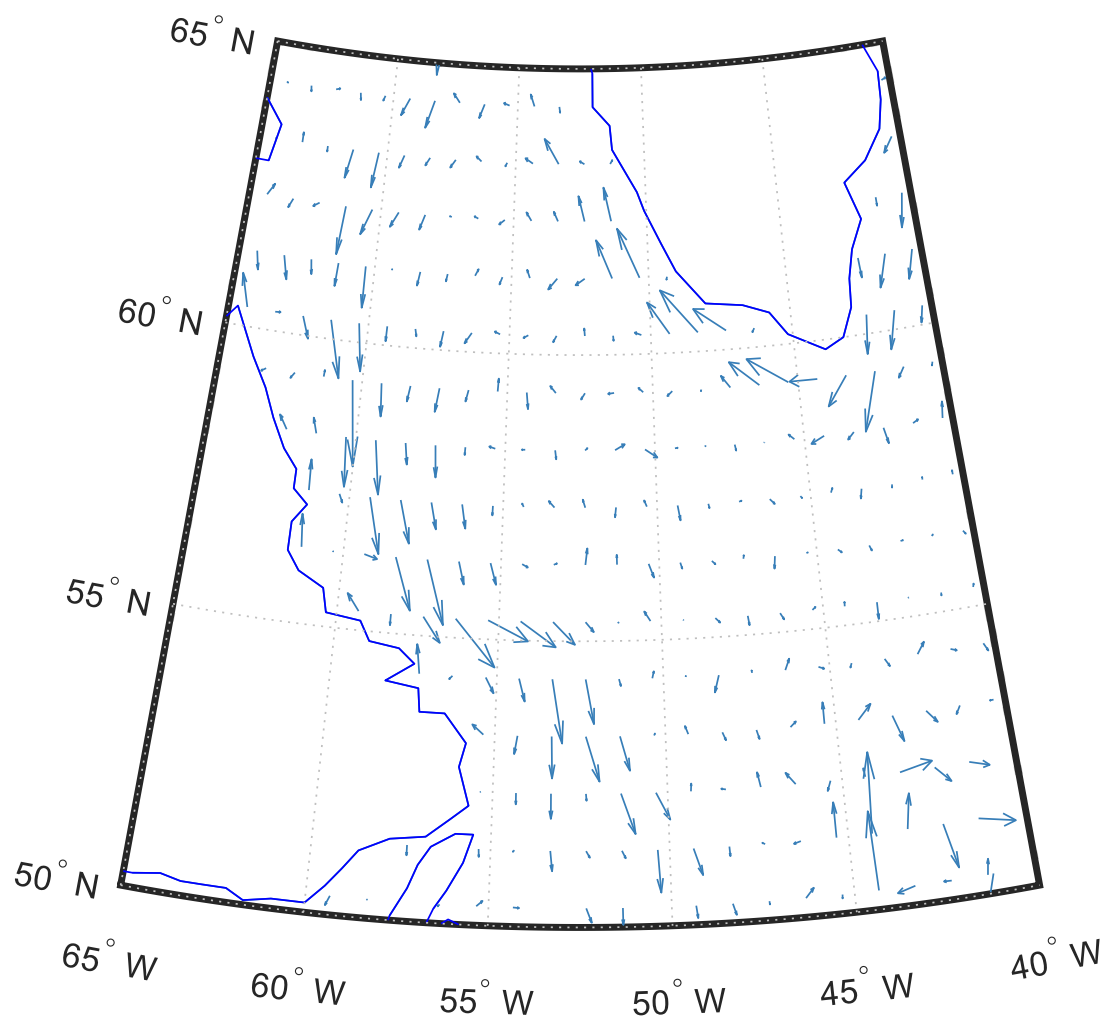

Figure S5. OSCAR satellite derived $1^{\circ}$ resolution sea-surface current vectors averaged for September 2017. 
Wind Speed $\left(\mathrm{m} \mathrm{s}^{-1}\right)$

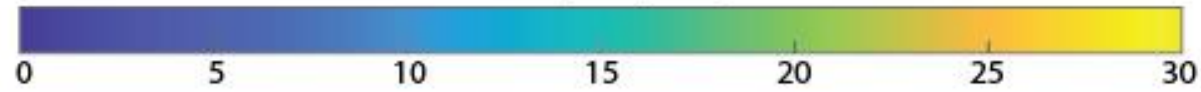

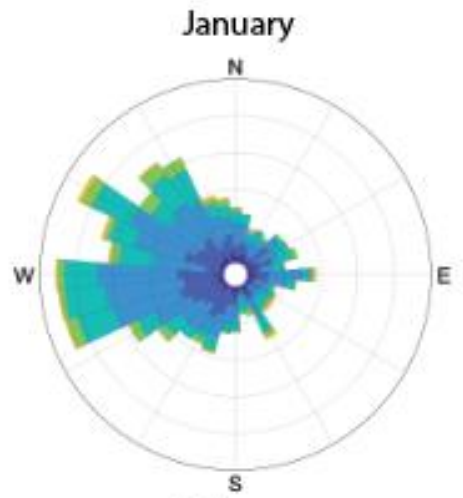

February

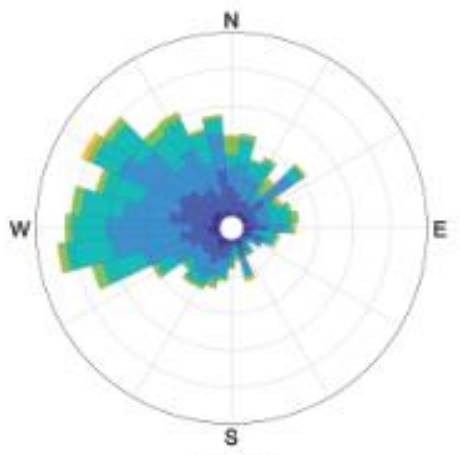

March

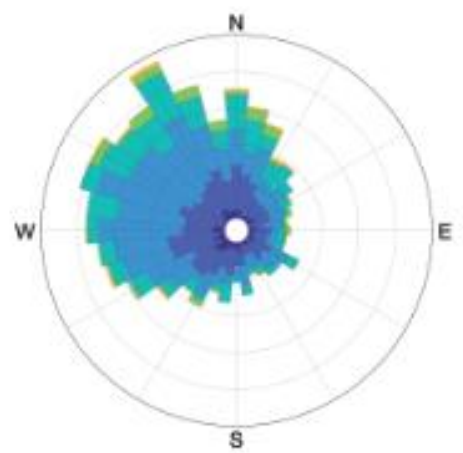

April

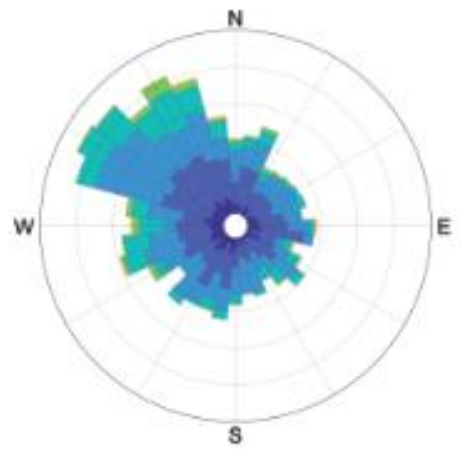

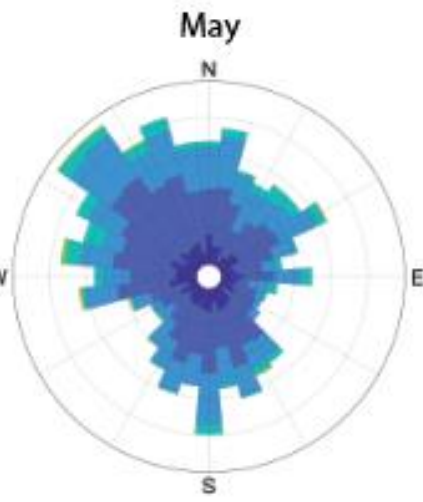

June

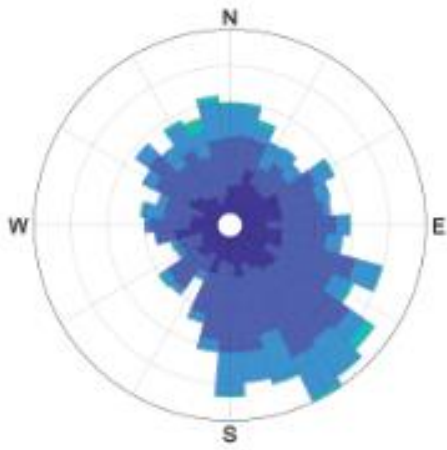

July

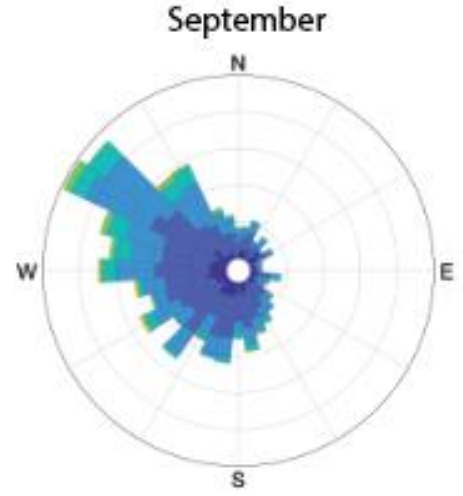

October

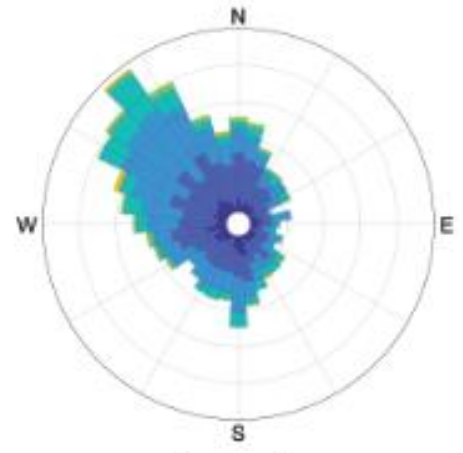

November

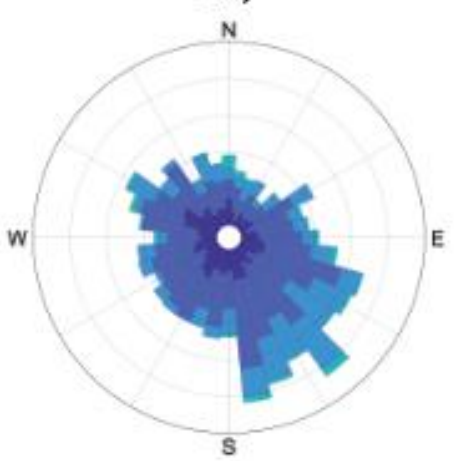

August

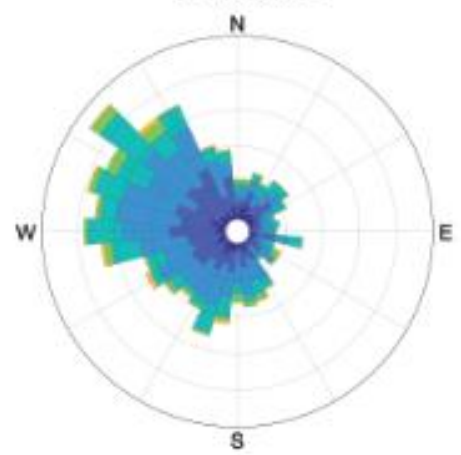

December
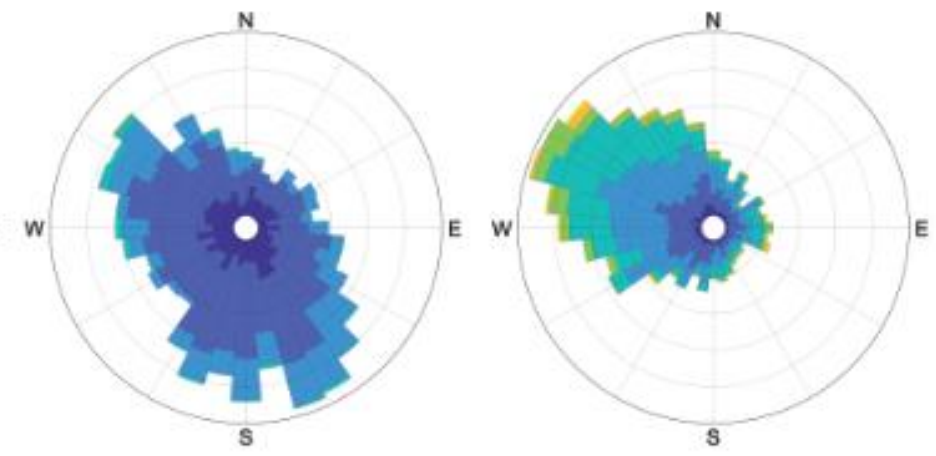
Figure S6. MERRA-2 hourly horizontal wind direction and speed by month from $2007-2020$ at $56^{\circ} \mathrm{N}$, $54^{\circ} \mathrm{W}$, which coincides with a point on the transition line between the closed-cell and cloud-free regions during NAAMES3. 


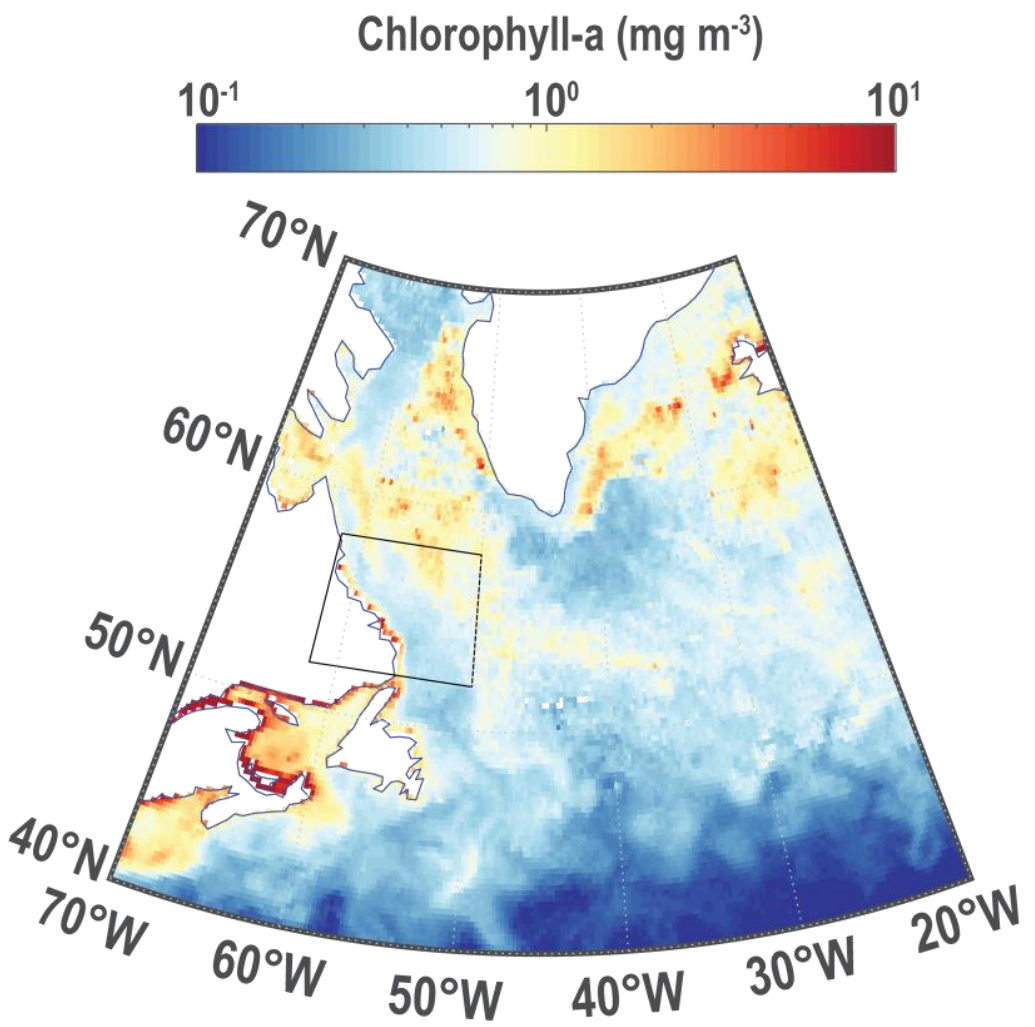

Figure S7. September 2017 averaged satellite chlorophyll-a. The boxed area represents the area analyzed in Figure 8. 
Cloud Fraction (\%) Chlorophyll-a $\left(\mathrm{mg} \mathrm{m}^{-3}\right)$
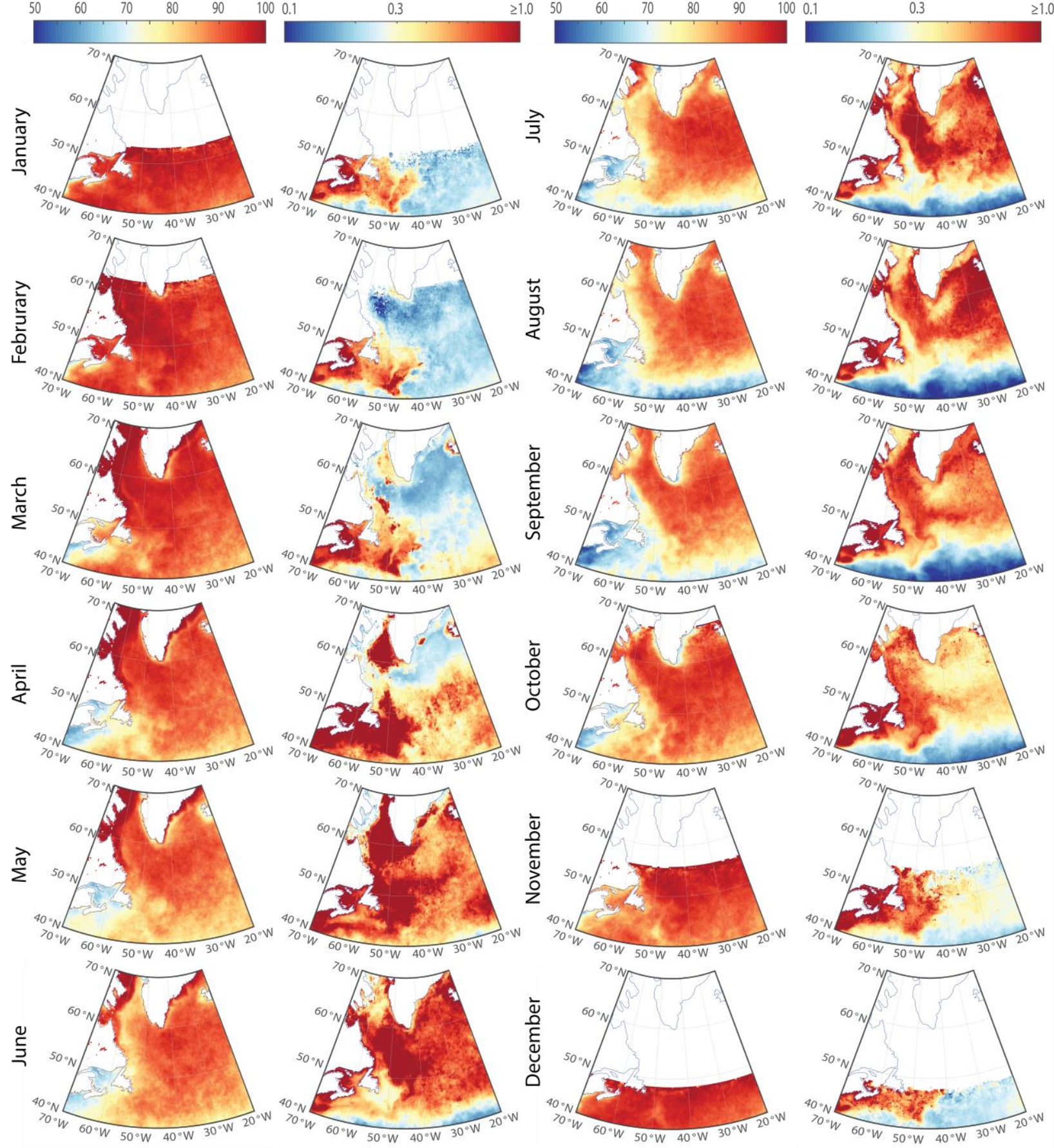

Figure S8. Monthly satellite derived cloud fraction and chlorophyll-a averaged over 2008-2019. 